\title{
A obra de arte e sua oscilação contraditória: a aura e o rastro
}

\author{
Izabela Leal - UFPA
}

Resumo: No livro $O$ que vemos, o que nos olha, Georges Didi-Huberman retoma o conceito benjaminiano de aura para entender a dinâmica da obra de arte e sua relação com a visualidade. Para Didi-Huberman, ao contemplarmos uma obra de arte, nosso olhar é cindido por um mecanismo de aproximação e afastamento, ou seja, há algo que nos olha naquilo que vemos. Nesse sentido, ao contemplarmos um objeto artístico, nós o capturamos com o nosso olhar, mas nesse mesmo ato de visão abre-se uma outra dimensão na qual nosso olhar nos é devolvido e agora é o objeto que nos captura. É interessante assinalar que Didi-Huberman constrói o seu edifício teórico associando essa dinâmica de aproximação e distância ao caráter aurático da obra de arte. A questão que pretendemos levantar aqui é se seria possível pensar que não haveria de fato uma oposição entre os conceitos benjaminianos de rastro e aura, sobretudo nessa dinâmica que caracteriza a obra de arte.

Palavras-chave: visualidade, aura, rastro

Vou tentar trazer aqui algumas reflexões de Didi-Huberman acerca da obra de arte que, segundo me parece, podem ajudar-nos a entender, tal como o tema do colóquio nos propõe, a produtividade dos conceitos benjaminianos de aura e rastro. Tenho a impressão, e é isso que tentarei mapear, que esses conceitos sofrem uma certa deformação ao serem incorporados pelo pensamento de Didi-Huberman em suas considerações sobre a imagem, de modo que há uma guinada que os aproxima e os funde, confunde. Não que em Benjamin não haja também uma certa fusão entre os dois, mas julgo que no arcabouço teórico de Didi-Huberman eles ganham uma amplitude maior, um certo afrouxamento, tornando-se como duas faces indissociáveis implicadas na dinâmica do olhar por ele proposta. Pretendo, pois, navegar pela oscilação dos conceitos, perseguindo o seu movimento em Benjamin e Didi-Huberman. Claro está que ao manipulá-los há também uma diferença de objetivos entre os dois pensadores, não são os mesmos interesses que estão em jogo, uma vez que o objetivo de Didi-Huberman é questionar a tarefa e o método do historiador da arte.

Parto de alguns quadros que a literatura nos oferece para discutir o poder da imagem sobre o espectador na produção de efeitos de sentido, e inicio com o famoso ensaio de Freud sobre a Gradiva, de Jensen.

Ao analisar a Gradiva, de Jensen, Freud (1907) nos relata a história de um jovem arqueólogo alemão que descobrira em Roma, num museu, um relevo com a imagem de uma moça que calçava leves sandálias e parecia surpreendida ao caminhar. O relevo que tanto o encantou, e cuja cópia foi posteriormente por ele adquirida, provavelmente chamava a sua atenção pelo modo incomum e gracioso que a moça manifestava ao andar, imaginando também que aquela imagem deveria remeter a Pompeia. Em seguida ele tem um sonho que o coloca na posição de espectador da destruição da cidade, no qual a jovem da gravura, chamada por ele Gradiva, também está presente. Logo depois ele decide ir à Itália e vê o seu trajeto, durante a própria viagem, ser alterado de Roma para Pompéia.

Já em Pompéia, o arqueólogo, num passeio realizado ao meio-dia, hora em que as ruas estavam desertas, julga ter acesso à vida que havia sido enterrada, mas nos faz observar que não é a ciência que lhe abriria essa porta:

ela ensina uma concepção fria e arqueológica do mundo e faz uso de uma linguagem filológica e morta, que em nada contribui para uma compreensão da qual participem o espírito, os sentimentos, o coração. Quem desejar atingi-la deve permanecer aqui, solitário, único ser vivente nessa calma abrasadora do meio-dia, entre as relíquias do passado, e ver, mas não com os olhos do corpo, e ouvir, mas não com os ouvidos físicos. E então... os mortos acordarão e Pompéia tornará mais uma vez à vida (FREUD, 1996, p. 24)

Não pretendo me estender na magnífica análise realizada por Freud sobre esse belo conto, mas seria importante observar que a partir desse ato de "ver, não com os olhos do corpo", se dará o desdobramento da história, o encontro do arqueólogo com a Gradiva e finalmente a descoberta de que essa moça, que estava passeando por Pompéia assim como ele, não era um fantasma, mas sim sua vizinha e companheira de brincadeiras na infância. O interesse do arqueólogo pela ciência subtraiu-o do convívio social e fez também com que se esquecesse da amiga, que continuou a alimentar um sentimento amoroso pelo antigo companheiro. No desenrolar do conto, o arqueólogo recupera a 
lembrança do passado recalcado e termina por beijar os lábios da moça, pedindo-a em casamento, mas não sem que pedisse também para observá-la enquanto andava, como a Gradiva do relevo, pelas ruas de Pompeia.

A partir desse exemplo do poder da visualidade sobre o olhante, ao qual retornarei, passo agora ao ensaio de Benjamin "A obra de arte na era de sua reprodutibilidade técnica" (1935/1936). Lá Benjamin diferencia o valor de culto de uma obra de arte do valor de exposição. O valor de culto, estando relacionado à função mágica da obra de arte, faz com que ela se afaste da visão, sua importância está relacionada à sua existência e não ao fato de ela poder ser vista. Benjamin relaciona o valor de culto à aura, justamente para investigar o papel que a fotografia desempenhou na transformação dos valores da arte. Para Benjamin, "o refúgio derradeiro do valor de culto foi o culto da saudade, consagrada aos amores ausentes ou defuntos. A aura acena pela última vez na expressão fugaz de um rosto, nas antigas fotos." (BENJAMIN, 1985, p. 174) A seguir Benjamin cita as fotos das ruas de Paris desertas de homens, feitas por Atget por volta de 1900, como exemplo do desaparecimento completo do homem - e consequentemente da aura -, exemplo limite da transformação do valor de culto em valor de exposição. Comparando a desertificação das ruas ao local de um crime, Benjamin comenta: "também esse local é deserto. É fotografado por causa dos indícios que ele contém. Essas fotos orientam a recepção num sentido predeterminado. A contemplação livre não lhes é adequada. Elas inquietam o observador, que pressente que deve seguir um caminho definido para se aproximar delas." (BENJAMIN, 1985, p. 174). É interessante observar que os indícios ou vestígios (spuren) estão associados a um potencial de inquietação, mas parece, em princípio, que esse estranhamento se deve mais à ausência do humano do que a qualquer outra característica intrínseca à imagem. O par de oposições entre os valores sociais da arte, seu valor ritual e seu valor de exposição, relacionam-se também ao tema da arte, que no caso do ritual era o próprio homem. Benjamin vê nas fotografias das ruas de Paris o exemplo máximo da transformação desse valor, já que as ruas são fotografadas pelos indícios que carregam em sua desertificação.

O que está em jogo na fotografia não é a existência única da obra, seu aqui e agora, mas o fato de que elas não se oferecem a uma contemplação livre, já que os indícios que elas contém causam uma certa estranheza ao observador. Mas para além de toda a discussão sobre a transformação da obra de arte em mercadoria, há algo que se diz nessa apresentação dos vestígios, algo que se inscreve como uma espécie de 'materialidade do tempo', para retomar os termos de Didi-Huberman em Devant l'image. Question posée aux fins d'une histoire de l'art (1990, p. 108), ou como "autos no processo da história" (BENJAMIN, 1985. p. 174), para ficar com a expressão de Benjamin. A presença desses vestígios faz com que se abra na imagem uma temporalidade outra, para a qual somos convocados não somente como receptores, mas também como intérpretes, exigindo de nós um trabalho típico da memória, um trabalho sobre os traços que promove a irrupção do passado no presente, quebrando a linearidade do tempo. A partir desse trabalho da memória o que estava esquecido, soterrado, agora vem à tona, alterando não só o passado como também o solo em que surge. Pois não é precisamente isso o que acontece no conto Gradiva, a partir da visão de uma Pompeia também deserta, esvaziada de gente e repleta de indícios?

Outro ponto fundamental enunciado nessa passagem de Benjamin diz respeito à capacidade que a obra artística tem de provocar uma inquietação no espectador. A noção de inquietação será desenvolvida logo adiante no mesmo ensaio quando o autor pensa a respeito da obra de arte realizada pelos dadaístas. Através de outro par de oposições, aqui o recolhimento e a distração, Benjamin assinala a aniquilação da aura da obra, realizada pelo dadaísmo, como um processo que anulava a possibilidade de recolhimento em prol da valorização da distração. Entretanto, me parece que há uma passagem um pouco inquietante no texto de Benjamin quando ele se refere à dinâmica do recolhimento e da distração jogada com o espectador. O autor nos diz que quem se recolhe diante de uma obra mergulha dentro dela e se dissolve, ao passo que quem se distrai diante de uma obra a faz mergulhar em si, absorvendo-a. Eu me pergunto aqui se essas duas atitudes estariam assim tão separadas, se elas definiriam objetos diferentes, ou se não é justamente na oscilação entre elas que encontraremos o caráter autêntico da obra de arte. Voltarei a este ponto.

No que se refere à distração, cumpre entender que ainda no mesmo ensaio o que Benjamin define com este termo é a capacidade que a obra tem de atingir o espectador, como um tiro. E afirma: 'tudo o que é percebido e tem caráter sensível é algo que nos atinge" (1985, p. 191) Ora, se aquilo que é percebido é algo que nos atinge, fica claro que há algo da ordem do corpo que se manifesta na visualidade, que através da visualidade é o corpo que é colocado em cena, o que Benjamin chama de qualidade tátil da obra. Também para Didi-Huberman o que está em jogo é o caráter tátil da obra de arte. Quando vemos um objeto, há algo nele que faz com que nosso olhar nos seja devolvido, algo do objeto nos olha, nos toca. Esse retorno do olhar sobre o olhante é fonte de inquietação, pois deixa emergir um movimento de reconhecimento e estranhamento, de algo que se mostra e algo que se perde. Quando vemos, algo nos escapa. E no entanto há sempre algo que reconhecemos. Observo aí uma pequena diferença em relação à oposição operacional estabelecida por Benjamin entre o recolhimento e a distração: numa certa medida capturamos o objeto; em outra, é ele que nos captura. Essas duas modalidades da visão se afirmam num único e simples ato de ver, não estão relacionadas a um tipo específico de objeto.

É pela via da inquietação, disso que na arte nos atinge, que eu gostaria de me aprofundar agora nas considerações de Didi-Huberman sobre a obra de arte. Um primeiro ponto a ser assinalado é que, para Didi-Huberman, a obra de arte estará necessariamente vinculada à dimensão da visualidade, e da dimensão da visualidade passamos 
imediatamente ao corpo. Retomando o conceito benjaminiano de imagem, Didi-Huberman a entende como algo que nos toca, sendo o toque uma espécie de limite último da visão. Não seria discrepante dizer que, do conceito de choque em Benjamin, passamos ao conceito de sintoma em Didi-Huberman, que também sofrerá, a meu ver, uma certa deformação, já que em Benjamin a experiência do choque está relacionada à descoberta da perda da aura, observada sobretudo em seus estudos sobre Baudelaire. A teoria do choque em Benjamin assinala o componente revolucionário e violento da imagem, ligado à concepção de história e de tempo. Esse poder da imagem, que constitui exatamente o que Benjamin chamará de imagem dialética é aquilo que opera a quebra na continuidade da história, fazendo emergir um tempo outro. Do mesmo modo, Didi-Huberman utiliza o conceito de sintoma para revelar o poder da imagem de quebrar o curso normal dos acontecimentos. O sintoma é a própria abertura da imagem em sua relação com a história, é fragmentação, crise, interrupção do tempo linear, revelando uma multiplicidade de tempos, um nó temporal que convoca um passado e um futuro.

Nesse sentido, uma imagem, mesmo que ela seja inegavelmente simples, mesmo que ela se apresente como algo sem profundidade, superficial, pode carregar em si um fundo de inquietação a partir do qual nos tornamos vítimas de uma despossessão do olhar. Para investigar esse poder da imagem de se apoderar do olhante, Didi-Huberman recorre ao conceito benjaminiano de aura, mas ao mesmo tempo se descolando da visão de Benjamin da obra de arte única, não reprodutível. ${ }^{i}$ A aura seria uma espécie de atributo visual da obra de arte que se manifesta na dinâmica entre o objeto olhado e o olhante; tal dimensão está necessariamente ligada à potência de inquietação provocada pelo objeto e inclui, necessariamente, os vestígios (spuren), traços que produzem uma reconfiguração incessante do passado, exigindo um trabalho da memória. A questão que aqui se inscreve, e que decorre de uma das definições de aura em Benjamin - "aparição única de uma coisa distante, por mais perto que ela esteja" (BENJAMIN, 1985, p. 170) -, implica também na "dupla distância"ii imposta simultaneamente pela aura e pelo rastro, se seguirmos os passos posteriores de Benjamin: "O rastro é a aparição de uma proximidade, por mais longínquo esteja aquilo que a deixou" (BENJAMIN, 2006, M 16a, 4).

É justamente a dinâmica da oscilação entre proximidade e distância que a obra de arte evidencia, dinâmica que revela uma operação de perda implicada na visualidade; a aparição de algo que só aparece tornando-se ao mesmo tempo distante, algo único e estranho, algo que impede o reconhecimento, que problematiza a ordem do saber. A partir daí, Didi-Huberman evoca um segundo aspecto da aura: "o poder do olhar atribuído ao próprio olhado pelo olhante: "isto me olha"' (DIDI-HUBERMAN, 2005, p. 148)

Gostaria agora de trazer um par de oposições que Didi-Huberman utiliza num esquema puramente operacional, e o desconstrói ao longo do livro, no já citado $O$ que vemos, o que nos olha. A oposição a que me refiro diz respeito a duas atitudes distintas diante do objeto artístico, chamadas por Didi-Huberman de crença e tautologia. $\mathrm{Na}$ atitude de crença, numa tentativa de negar o vazio e escapar da angústia, o olhante investe o objeto da visão de algo que está para além do visto, ele vê além do que vê. Como se a razão tentasse se erigir acima do abismo aberto pela sensação, fornecendo um sentido suplementar e estável ao objeto.

Passo agora a um recorte do inquietante Ecuador, de Henri Michaux, espécie de livro de viagens e diário de bordo, recheado de poemas e digressões. Numa delas, o poeta, que era também pintor, reflete ironicamente sobre o comportamento do público numa exposição de pintura, e percebemos essa manobra que é ver além do objeto, suturando o vazio angustiante da forma que inquieta. O episódio toma como referência, muito provavelmente, uma pintura abstrata.

\section{Quadro 2:}

É preciso escutar o público numa exposição de pintura. Frequentemente, depois de ter longamente investigado, alguém, apontando o dedo em direção ao quadro, diz: "É uma macieira", e sentimos o seu alívio.

Ele discerniu uma macieira! Eis um homem feliz. (MICHAUX, 1968, p. 29)

Nessa passagem do livro de Michaux somos apresentados a um homem que distingue uma macieira a partir do informe da forma. O que ele sente? Alívio e felicidade. Vemos aqui dois estados emocionais complementares, a felicidade sendo uma consequência do alívio. Mas por que alívio? Porque a imagem se apresenta como fonte de inquietação, como uma aporia. A atitude que se descortina no exemplo de Michaux, ainda que se afaste dos exemplos típicos trabalhados por Didi-Huberman no sentido do que ele chama de atitude de crença, que pressupõe toda uma passagem pela iconografia cristã e pela relação metafísica e teleológica com a imagem, não deixa de ser igualmente eloquente como tentativa de preenchimento do vazio, daquilo que se apresenta como um problema para a razão. Daí que a felicidade em questão provenha do que Didi-Huberman chamaria de uma vitória da linguagem sobre o olhar, culminando na operação de nomear, de transformar o informe da pintura na forma de uma macieira, passível então de ser designada. Uma vez nomeada, a imagem é fixada numa determinada representação, sua oscilação é abolida e a própria distância que existia entre ela e o olhante desaparece. O espectador em questão se apodera perversamente da imagem, faz desaparecer o seu caráter aurático. Não que aqui, nesse exemplo recortado de Michaux, se trate da 
promessa de que exista algo transcendental para além da imagem vista, mas de todo modo fica claro o mecanismo de fazer com o que sentido, na sua acepção semiótica, se sobreponha ao sentido em sua acepção sensorial, desfazendo, no mesmo ato, o caráter dialético da imagem, que é necessariamente a existência de uma ponte, uma oscilação entre essas duas concepções de sentido.

A outra atitude diante da imagem investigada por Didi-Huberman é a que ele chamou de tautológica. Nesse caso o caráter aurático da imagem é também negado, como se fosse possível a existência de uma imagem absolutamente simples, que remetesse apenas ao visível, sem produzir a partir daí nenhum tipo de sentido. Claro está que este jogo de oposições deve ser ultrapassado, pois mesmo uma imagem aparentemente simples não deixará de produzir efeitos de sentido. A tautologia - "what you see is what you see" - é uma falácia. Ao sair do impasse entre crença e tautologia, Didi-Huberman formula, a partir de Benjamin, o conceito de imagem crítica, que é o desdobramento da imagem em pensamento e memória, implicando a sua dimensão de temporalidade.

Retomo agora o conto da Gradiva analisado por Freud. Sem me preocupar em refazer o percurso do estudo sobre os mecanismos de repressão, que é o interesse principal do psicanalista, gostaria de reter a implicação metafórica do conto, a emergência de algo soterrado e esquecido que alterará irremediavelmente o curso dos acontecimentos. Nesse sentido, nenhuma profissão caberia tão bem ao protagonista como a arqueologia, profissão que joga o tempo todo com algo que está morto e, depois de escavado, retorna à vida, alterando também o próprio solo e o cenário em que emerge. A imagem da Gradiva seria aqui, para Didi-Huberman, o típico exemplo da imagem crítica, liberada tanto da crença como da tautologia, imagem que nos interroga e exige uma resposta, mas uma resposta que modificará o sujeito que responde a ela. Nessa oscilação entre reconhecimento e estranhamento há a produção de uma temporalidade nova.

O exemplo da Gradiva conjuga inegavelmente as duas acepções de sentido contidas na imagem crítica, o desdobramento do sensorial no semiótico, sem que um se sobreponha ao outro. O sentido visual é um fundo que interroga o sujeito e a partir do qual determinado tipo de saber é construído, sendo que a construção desse saber altera o próprio sujeito que trabalha na escavação do passado, ao contrário do que acontece com o observador guiado pela atitude de crença, que não se modifica a partir da experiência da imagem. Mas cabe aqui ressaltar que, para DidiHuberman, mesmo a imagem mais simples pode ser portadora de um caráter aurático, sendo que esse caráter aurático não provém de nenhuma particularidade específica da imagem; ele decorre pura e simplesmente da relação dialética com o visível, a própria relação com o tempo e a morte, daí que Didi-Huberman enfatize a necessidade de secularização da aura.

Para finalizar, gostaria de trazer uma passagem conhecidíssima de Em busca do tempo perdido. Trata-se precisamente do momento em que o escritor Bergotte decide dirigir-se ao museu para contemplar o quadro "Vista de Delft', de Vermeer, que ele julgava conhecer bem, mas pelo qual nutre uma curiosidade nova despertada após a leitura de uma crítica que trazia o elogio de um pequeno pedaço de muro amarelo pintado com extremo cuidado. Conhecemos bem o desfecho dessa passagem: a morte do escritor.

Quadro 3:

Enfim chegou diante do Ver Meer [sic] [...], reparou pela primeira vez numas figurinhas vestidas de azul, na tonalidade cor de rosa da areia e finalmente na preciosa matéria do pequenino pano de muro amarelo. As tonteiras aumentavam; não tirava os olhos [...] do precioso panozinho de muro. 'Assim é que eu deveria ter escrito', dizia consigo. 'Meus últimos livros são demasiado secos, teria sido preciso passar várias camadas de tinta, tornar a minha frase preciosa em si mesma, como este pedacinho de muro.' Não lhe passava, porém, despercebida a gravidade das tonteiras. Em celestial balança lhe aparecia, num prato a sua própria vida, no outro o panozinho de muro tão bem pintado de amarelo. (PROUST, 1988, p. 173)

Lembremos que na cena em questão a experiência de perturbação não será produzida pela visão total do quadro, que o escritor já conhecia muito bem, mas por aquilo que constitui uma forma aparentemente simples, um pequeno pedaço de muro amarelo, um detalhe ínfimo. Nenhuma forma humana está aqui presente, nada que pudesse remeter de um modo mais explícito a algo que estivesse tipicamente relacionado à aura do objeto. $\mathrm{O}$ muro, além de ser uma parte muito pequena do quadro, é uma superfície lisa, sem profundidade aparente. E, no entanto, Bergotte viu naquele muro alguma coisa, ou para dizer de modo mais correto, alguma coisa naquele muro o olhou, alguma coisa se apossou dele. E em toda a descrição que temos da cena, o que foi que o olhou? Eu ensaiaria como resposta: as várias camadas de tinta que compõem o muro, e que deveriam estar presentes também nas frases que o autor escrevia: "teria sido preciso passar várias camadas de tinta". Camadas de tinta, a expressão não poderia ser mais significativa. Tratase da superfície que adquire profundidade, que remete ao acúmulo do tempo ${ }^{\mathrm{iii}}$, aos traços da sedimentação que agora explodem no espaço inscrito entre olhante e olhado, produzindo também uma ponte - e aqui seria melhor falar em cisão, mas toda ponte é também uma cisão - entre o sentido sensorial e o semiótico, sendo que agora, nesse exemplo, o sentido semiótico não pode mais recobrir o sensorial, há uma espécie de falência do mundo da linguagem diante da 
imagem, e é justamente a impotência da palavra, seu fracasso, que se volta sobre o escritor, fornecendo a única resposta possível diante do vazio absoluto: a morte.

Enfim, penso que na passagem do conceito de imagem dialética, em Benjamin, ao conceito de imagem crítica, em Didi-Huberman, há uma operação de fusão entre os conceitos de aura e rastro. O caráter aurático da imagem, para Didi-Huberman, é o que nos convoca nesse movimento de mão dupla entre olhar e ser olhado pelo objeto, como se a imagem produzisse uma exigência de sentido, como se demandasse do olhante uma espécie de trabalho; o trabalho da memória que o protagonista da Gradiva realiza a partir da visão do relevo. Nesse sentido, a imagem é uma formação crítica, ela faz com que nos detenhamos diante dela, solicitando que nos tornemos intérpretes. A dimensão da aura em Didi-Huberman inclui, a meu ver, também o rastro, como se o rastro fosse um tipo de suporte material a partir do qual o campo aurático se abre, constituindo a dinâmica da imagem presente na obra de arte. Pois como afirma DidiHuberman em $O$ que vemos, o que nos olha, é preciso "reconhecer na própria aura uma instância dialética." (DIDIHUBERMAN, 2005, p. 154) É a partir do caráter aurático da imagem, que conjuga contiguidade e lonjura, aproximação e afastamento, que Didi-Huberman condiciona a oscilação imposta pela cisão do ver à sensação de angústia diante daquilo que não podemos apreender, daquilo que nos escapa, do vazio. Trata-se justamente de perceber que a visualidade revela um campo fundado na perda, pois a visão está sempre perturbada pela imagem, pelo horizonte da morte.

\begin{abstract}
In the book, Ce que nous voyons, ce qui nous regarde (1992) Georges Didi-Huberman takes the benjaminian concept of aura to understand the dynamics of the artwork and its relation to the visuality. Didi-Huberman affirms that in contemplating anwork of art, our vision is split by a mechanism of approach and separation, there is something that look at us in what we see. In this sense, when we contemplate na art object, we capture it with our look, but this same act of vision opens up another dimension in which our gaze is returned and now is the object that captures us. It is interesting to note that Didi-Huberman builds his theoretical construct associating this process of approach and separation to the auratic character of artwork. The question we want to raise is wheter it is possible to think that there is in fact, no opposition between the benjaminian concepts os trace and aura, especially in this dynamic that characterizes the work of art.
\end{abstract}

Key-words: visuality, aura, trace

\title{
Referências bibliográficas
}

AGAMBEN, Giorgio. Estâncias. A palavra e o fantasma na cultura ocidental. Belo Horizonte: Editora UFMG, 2007 BENJAMIN, Walter. "A obra de arte na era de sua reprodutibilidade técnica". In: Magia e técnica, arte e política. Obras escolhidas Vol I. Tradução Sergio Paulo Rouanet. São Paulo: Brasiliense, 1985 . Passagens. São Paulo: Imprensa oficial do estado/UFMG, 2006

DIDI-HUBERMAN, Georges. O que vemos, o que nos olha. São Paulo: Ed. 34, 1998

- Devant l'image. Question posée aux fins d'une histoire de l'art. Paris: Minuit, 1990

. Devant le temps. Histoire de l'art et anachronisme des images. Paris: Minuit, 2000

FREUD, Sigmund. "Delírios e sonhos na Gradiva de Jensen". In: Edição Standard Brasileira das Obras Psicológicas Completas de Sigmund Freud. Rio de Janeiro: Imago, 1996.

MICHAUX, Henri. Ecuador. Paris: Gallimard, 1968

PROUST, Marcel. A prisioneira. Porto Alegre: Globo, 1988 


\section{Notas}

\footnotetext{
i Também Giorgio Agamben, em Estâncias. A palavra e o fantasma na cultura ocidental, sugere uma guinada do conceito benjaminiano de aura, postulando que Benjamin não se deu conta de que a 'decadência da aura' do objeto artístico produziu uma 'nova aura', concedendo à obra de arte um outro tipo de autenticidade, agora análoga à mercadoria.

ii Termo utilizado por Didi-Huberman para formular a dialética do ver discutida no livro $O$ que vemos, o que nos olha.

iii iii Como assinala Didi-Huberman, "diante da imagem estamos sempre diante do tempo" (HUBERMAN, 2000, p. 9)
} 